\title{
Cervical myelopathy due to subaxial calcium pyrophosphate dihydrate (CPPD) deposition with simultaneous asymptomatic crowned dens syndrome: two case reports
}

Dong-Gune Chang ${ }^{1}$, Jong-Beom Park ${ }^{2,3^{*}}$ (D), Ho-Young Jung ${ }^{2}$ and Kyung Jin Seo ${ }^{4}$

\begin{abstract}
Background: There are few reports of cervical myelopathy caused by an attack of subaxial calcium pyrophosphate dihydrate (CPPD) deposition. Moreover, there has been no report on cervical myelopathy by subaxial CPPD deposition with simultaneous asymptomatic crowned dens syndrome (CDS) at the same time.

Case presentation: The first case was a 68-year-old male complaining of cervical myelopathic symptoms. Plain radiographs, computed tomography (CT) and magnetic resonance imaging (MRI) findings revealed spinal cord compression by calcified round lesions at C4 as well as a calcified lesion behind the dens. The second case was a 77year-old female complaining of cervical myelopathic symptoms. Plain radiographs, CT and MRI findings revealed spinal cord compression by calcified round lesions at C3 and C4 as well as a calcified lesion behind the dens. In both cases, we believed that the calcified lesion behind the dens was an asymptomatic lesion. Therefore, the first patient received decompressive laminectomy of C3 and C4, removal of calcified round lesions, and posterior fixation from C3 to C5 due to associated kyphosis. The second patient underwent decompressive laminectomy of $\mathrm{C} 3$ and $\mathrm{C} 4$ and removal of calcified round lesions. Microscopic examination under polarized light showed dark blue calcifications with rhomboid crystals that were positively birefringent. The findings were consistent with those of CPPD.
\end{abstract}

Conclusions: This is the first study to report cervical myelopathy caused by subaxial CPPD deposition with simultaneous asymptomatic CDS. Surgical removal of the subaxial CPPD deposition alone achieved a satisfactory surgical outcome without recurrence.

Keywords: Cervical myelopathy, Subaxial calcium pyrophosphate dehydrate, Crowned dens syndrome

\footnotetext{
*Correspondence: spinepjb@catholic.ac.kr

${ }^{2}$ Department of Orthopaedic Surgery, College of Medicine, The Catholic

University of Korea, Seoul, South Korea

${ }^{3}$ Department of Orthopaedic Surgery, Uijeongbu St. Mary's Hospital, College

of Medicine, The Catholic University of Korea, 271 Cheonbo-ro, Uijeongbu-si, Gyeonggi-do 11765, South Korea

Full list of author information is available at the end of the article
}

(c) The Author(s). 2020 Open Access This article is licensed under a Creative Commons Attribution 4.0 International License, which permits use, sharing, adaptation, distribution and reproduction in any medium or format, as long as you give appropriate credit to the original author(s) and the source, provide a link to the Creative Commons licence, and indicate if changes were made. The images or other third party material in this article are included in the article's Creative Commons licence, unless indicated otherwise in a credit line to the material. If material is not included in the article's Creative Commons licence and your intended use is not permitted by statutory regulation or exceeds the permitted use, you will need to obtain permission directly from the copyright holder. To view a copy of this licence, visit http://creativecommons.org/licenses/by/4.0/ The Creative Commons Public Domain Dedication waiver (http://creativecommons.org/publicdomain/zero/1.0/) applies to the data made available in this article, unless otherwise stated in a credit line to the data. 


\section{Background}

Calcium pyrophosphate dehydrate (CPPD) deposition is characterized by the accumulation of CPPD crystals in articular and periarticular tissues [1-7]. CPPD deposition in the cervical spine has been previously described and there are few reports of cervical myelopathy caused by subaxial CPPD deposition [815]. Crowned dens syndrome (CDS), which is known as retro-odontoid CPPD deposition, may usually present neck pain and stiffness and cause progressive spinal cord compression and myelopathy with disease progression [8-15].

However, to the best of our knowledge, there has been no report on cervical myelopathy caused by subaxial CPPD deposition with simultaneous asymptomatic CDS at the same time. Therefore, we hereby report two cases of cervical myelopathy caused by subaxial CPPD deposition with simultaneous asymptomatic CDS that were successfully treated by surgical removal of the subaxial CPPD deposition alone.

\section{Case presentation}

\section{Case 1}

A 68-year-old male presented with neck pain (neck visual analogue scale [VAS] score: 3), bilateral radiating arm pain (arm VAS score: 7/7), and gait disturbance for 6 weeks. He had no history of recent head or neck injuries. Neurological examination revealed a spastic gait, hand clumsiness, and exaggerated deep tendon reflexes in the bilateral upper and lower extremities. Pathologic Babinski sign and ankle clonus were present. Muscle strength of both lower extremities was decreased. Grip and release test was 18 times per $20 \mathrm{~s}$. Modified Japanese Orthopaedic Association (mJOA) score was 9. However, he had no dysuria or constipation. Sagittal (Fig. 1a and b) and axial (Fig. 1c and d) magnetic resonance imaging
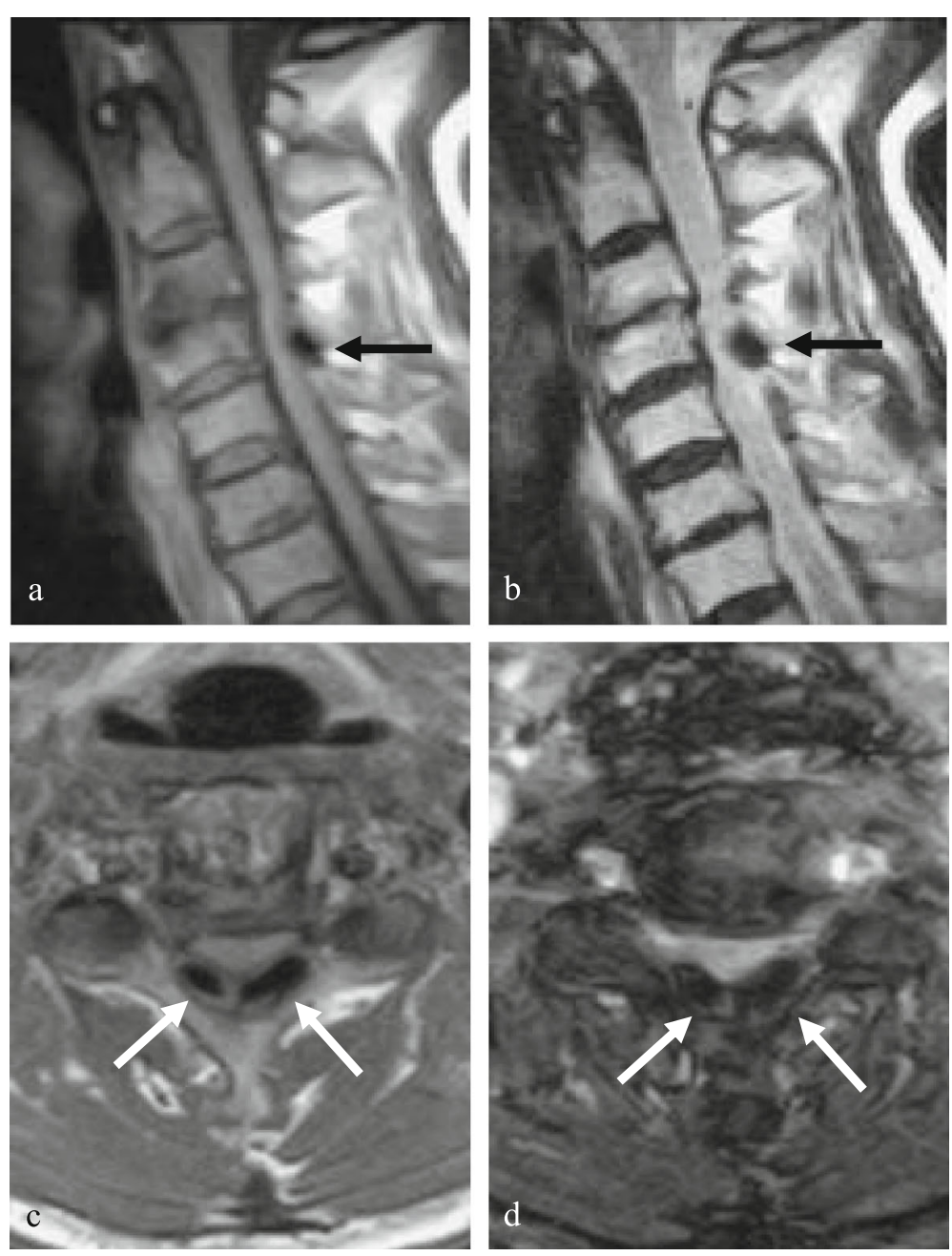

Fig. 1 Sagittal (a and b) and axial (c and d) MRI demonstrated spinal cord compression by dark round lesions (black and white arrows) at C4 which appeared as a low signal mass on both T1 (a and $\mathbf{c}$ ) and T2 (b and $\mathbf{d}$ ) weighted images 

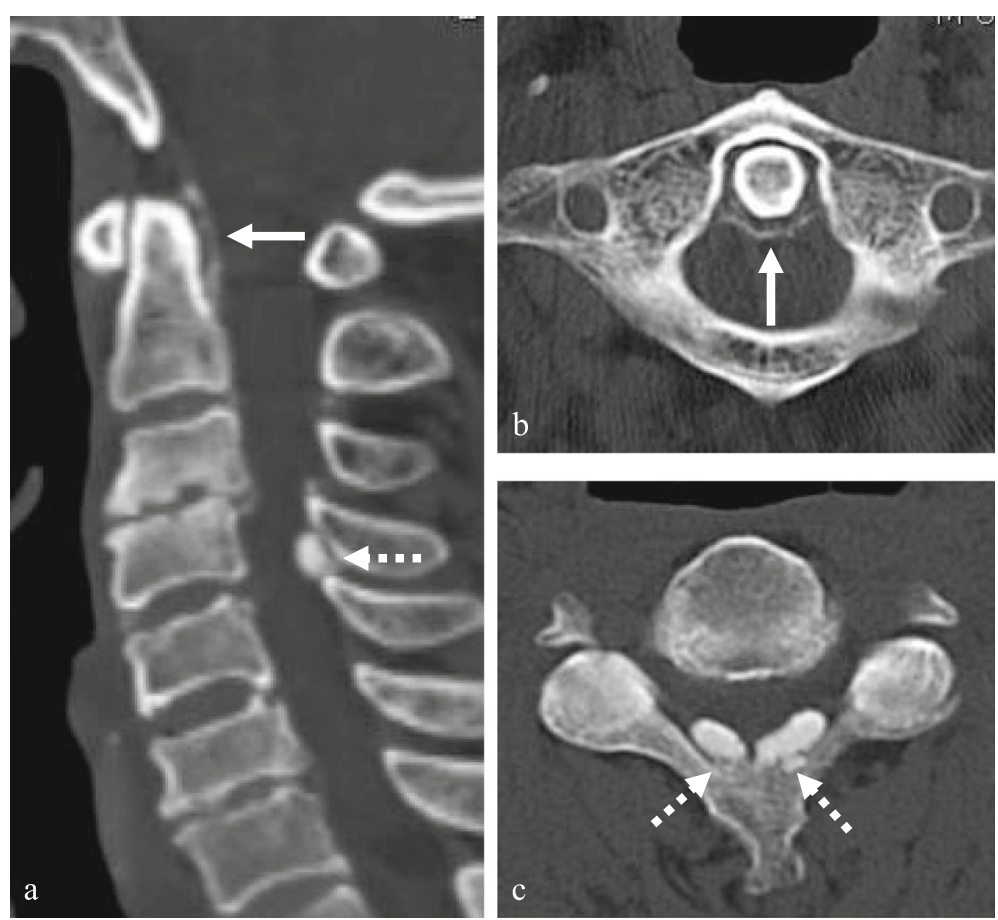

Fig. 2 Sagittal and axial CT scans revealed calcified lesion behind the dens ( $\mathbf{a}$ and $\mathbf{b}$ ) (white arrows) and spinal cord compression by calcified round lesions (a and $\mathbf{c}$ ) at C4 (dotted white arrows)

(MRI) showed spinal cord compression by dark round lesions at $\mathrm{C} 4$ which appeared as a hypointense mass on both T1 and T2 weighted images. Sagittal and axial computed tomography (CT) scans showed a calcified lesion behind the dens (Fig. 2a and b) and spinal cord compression by round calcified lesions at C4 (Fig. 2a and $\mathrm{c}$ ). Lateral radiograph of the cervical spine showed round calcified lesions at the lamina of $\mathrm{C} 4$ (white arrow) and spondylotic changes and disc space narrowing of C3-C4 (Fig. 3a). The calcified lesion behind the dens was thought to be an asymptomatic lesion, and the patient received decompressive laminectomy at $\mathrm{C} 3$ and $\mathrm{C} 4$, removal of round calcified lesions, and posterior fixation with lateral mass screws from $\mathrm{C} 3$ to $\mathrm{C} 5$ (Fig. 3b).

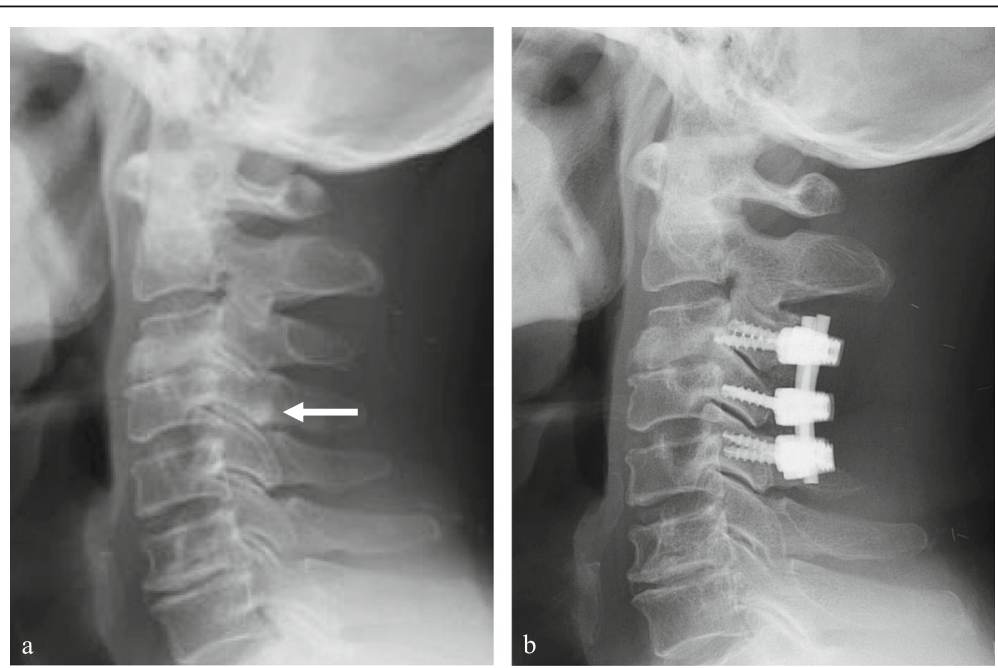

Fig. 3 Lateral radiograph (a) of the cervical spine showed round calcified lesions at the lamina of C4 (white arrow) and spondylotic changes and disc space narrowing of C3-C4. Lateral radiograph (b) of the cervical spine showed decompressive total laminectomy of C3 and C4 and posterior fixation with lateral mass screws from C3 to C5 

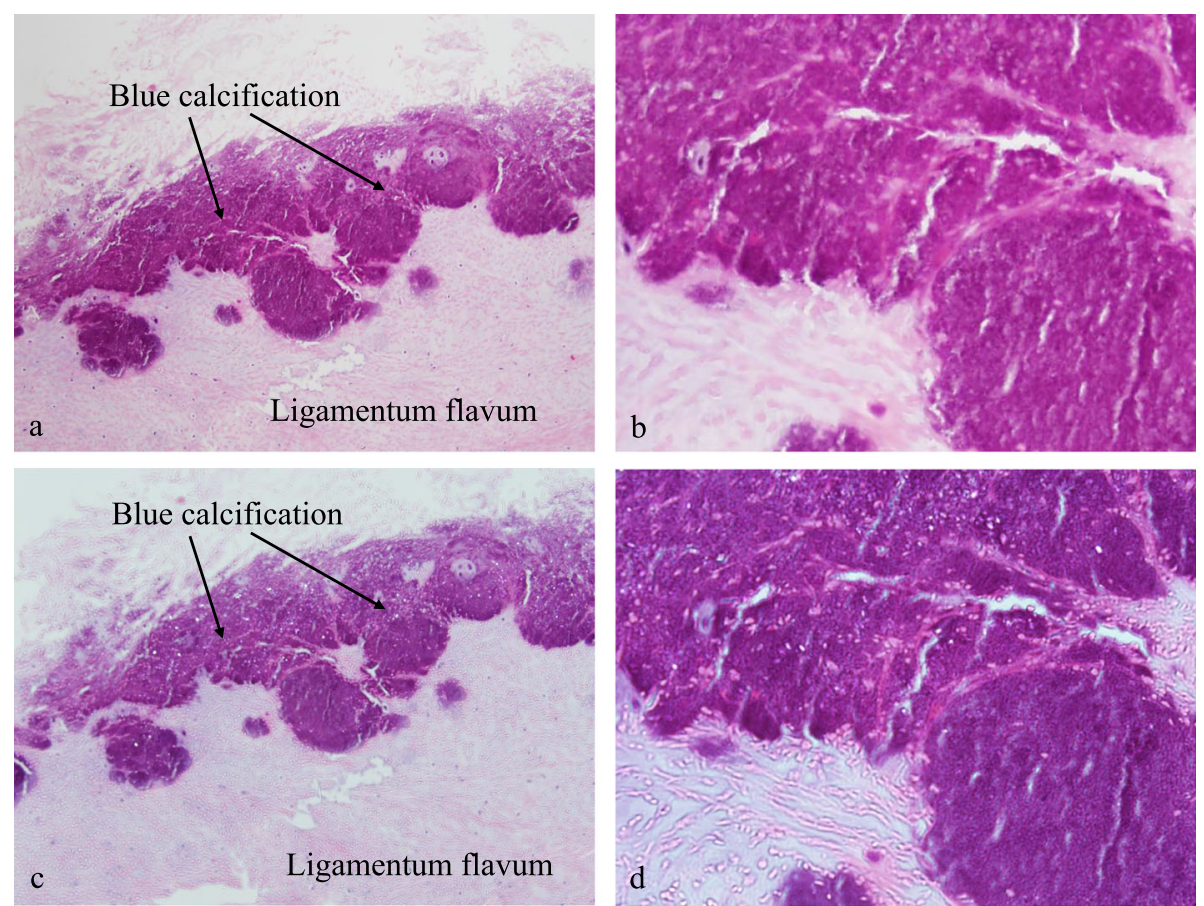

Fig. 4 Microscopic evaluation $(\times 100, \mathbf{a} ; \times 400$, b) of the surgical specimen demonstrated degenerated ligamentum flavum with dark blue calcifications representing chondrocalcinosis. Microscopic evaluation $(\times 100, \mathbf{c} ; \times 400$, d) of the surgical specimen under polarized light showed rhomboid crystals that were positively birefringent in blue calcification area

Microscopic evaluation (× 100, Fig. 4a; × 400, Fig. 4b) of the surgical specimen demonstrated degenerated ligamentum flavum with dark blue calcifications representing chondrocalcinosis. Microscopic evaluation $(\times 100$, Fig. $4 \mathrm{c} ; \times 400$, Fig. $4 \mathrm{~d})$ of the surgical specimen under polarized light showed rhomboid crystals that were positively birefringent in the blue calcification area. The findings were consistent with CPPD. The patient's myelopathic symptoms were significantly improved after surgery to mJOA of 14 with a recovery rate of $56 \%$ and showed a satisfactory surgical outcome without recurrence at a 5-year follow-up.

\section{Case 2}

A 77-year-old female presented with neck pain (neck VAS score: 4), bilateral radiating arm pain (arm VAS score: 6/6), and gait disturbance for 10 days. She had no history of recent head or neck injuries. Neurological examination revealed a spastic gait, hand clumsiness, and exaggerated deep tendon reflexes in the bilateral upper and lower extremities. Pathologic Babinski sign and ankle clonus were present. Muscle strength of both lower extremities was diffusely decreased. Grip and release test was 14 times per $20 \mathrm{~s}$. mJOA score was 8 . However, she had no dysuria or constipation. Sagittal (Fig. 5a and b) and axial (Fig. 5c and d) MRI showed spinal cord compression by dark round lesions at the laminae of $\mathrm{C} 3$ and $\mathrm{C} 4$ which appeared as hypointense masses on both T1 and T2 weighted images. Sagittal and axial CT scans showed a calcified lesion behind the dens (Fig. 6a and b) and spinal cord compression by round calcified lesions at C3 and C4 (Fig. 6a and c). Lateral radiograph of the cervical spine showed round calcified lesions at the laminae of $\mathrm{C} 3$ and C4 (Fig. 7a). The patient received decompressive laminectomy of $\mathrm{C} 3$ and $\mathrm{C} 4$ and removal of round calcified lesions. An intraoperative clinical photo (Fig. $7 \mathrm{~b}$ ) showed round calcified lesions compressing the spinal cord. Microscopic evaluation $(x$ 200, Fig. $8 \mathrm{a} ; \times 400$, Fig. $8 \mathrm{~b}$ ) of the surgical specimen demonstrated a degenerated ligamentum flavum with dark blue calcifications representing chondrocalcinosis. Microscopic evaluation $(\times 200$, Fig. 8c; $\times 400$, Fig. 8d) of the surgical specimen under polarized light showed rhomboid crystals that were positively birefringent in the blue calcification area. The findings were consistent with CPPD. The patient's myelopathic symptoms were significantly improved after surgery to mJOA of 13 with a recovery rate of $50 \%$ and showed a satisfactory surgical outcome without recurrence at a 2-year follow-up.

\section{Discussion and conclusions}

CPPD deposition is a crystal arthropathy primarily affecting the peripheral joints, most commonly the wrist and knee. However, CPPD deposition in the cervical 

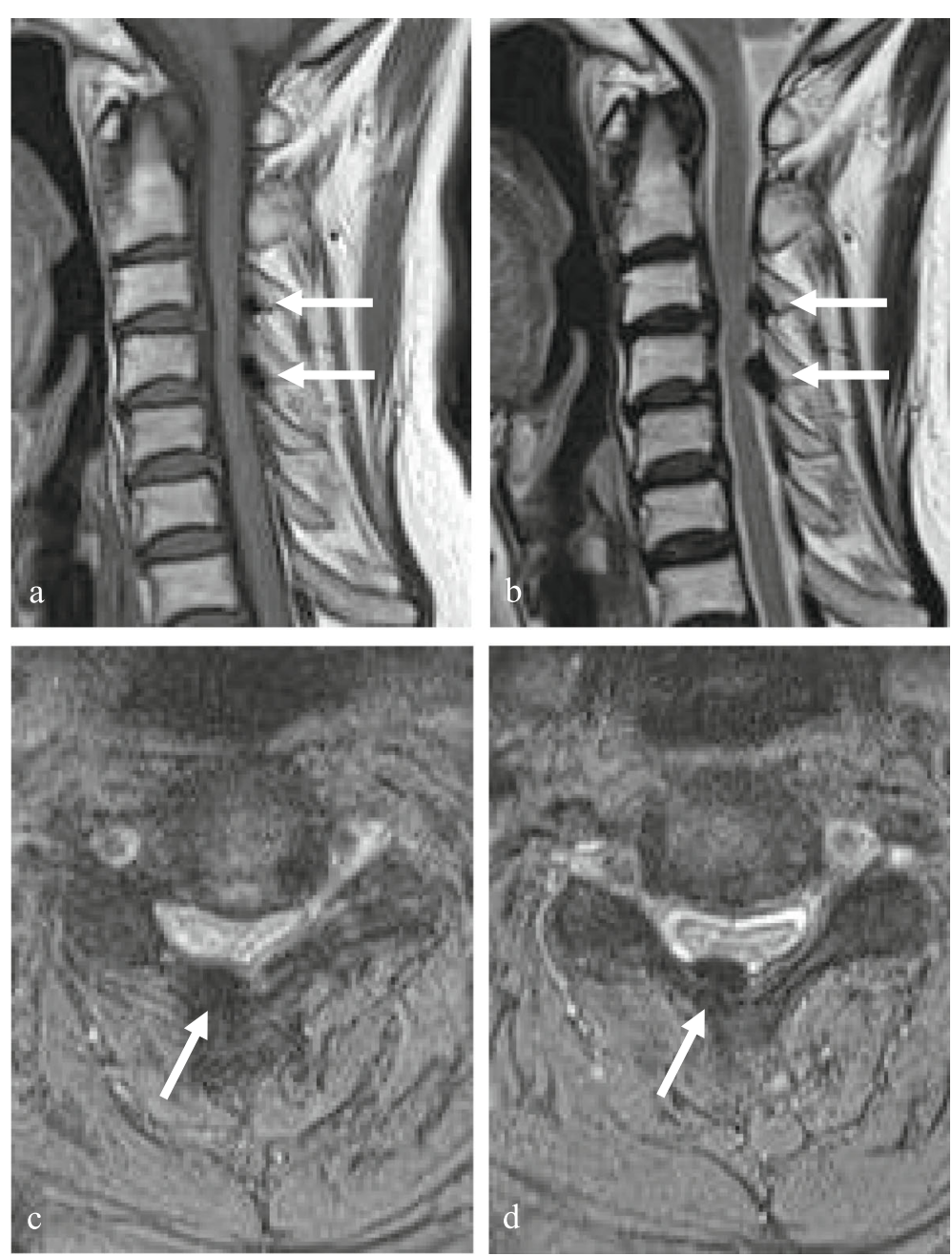

Fig. 5 Sagittal (a and $\mathbf{b}$ ) and axial (c and $\mathbf{d}$ ) MRI showed spinal cord compression by dark round lesions at the laminae of C3 and C4 (white arrows)

spine is a rare entity [1-7]. CPPD deposition in the cervical spine is an unusual cause of cervical spinal cord compression and myelopathy. Retro-odontoid CPPD deposition may lead to acute pseudogout and can be visualized as calcifications that surround the apex of the dens, and therefore, it is known as "CDS" [8-13]. This entity may manifest itself in a variety of ways, but it usually presents as acute neck pain and stiffness $[8,10,16]$. With disease progression, it may present as a massoccupying lesion and cause progressive cervical spinal cord compression and myelopathy $[11,12]$.

CPPD deposition of the spine, including CDS, has been previously described, but it is very unusual in the lower cervical spine $[2,3,5,14,15]$. There are very few reports of cervical myelopathy caused by subaxial CPPD deposition and there has been no report on cervical myelopathy by subaxial CPPD deposition with simultaneous asymptomatic CDS at the same time. To the best of our knowledge, this is the first report on cervical myelopathy caused by subaxial CPPD deposition with simultaneous asymptomatic CDS at the same time.

The CDS is characterized by various clinical manifestations of cervical pain and neck stiffness and myelopathy. Calcification can occur at not only the cruciform ligament but also the transverse, alar and apical ligaments [8-13]. Cervical CPPD deposition may produce a unique type of neck pain from the suboccipital region to the posterior neck bilaterally with restricted motion in rotation [2, 17-21]. Furthermore, compressive cervical myelopathy can manifest, especially when CPPD deposition occurs at the ligamentum flavum $[14,15]$. In each of the present cases, the patient had asymptomatic CDS. A calcified lesion behind the dens did not compress the spinal cord, and the patient complained of only mild neck pain with the neck VAS score of 3-4 without myelopathy. The patients also showed C3 and C4 CPPD deposition, resulting in spinal cord compression causing cervical myelopathy symptoms, such as hand clumsiness, 

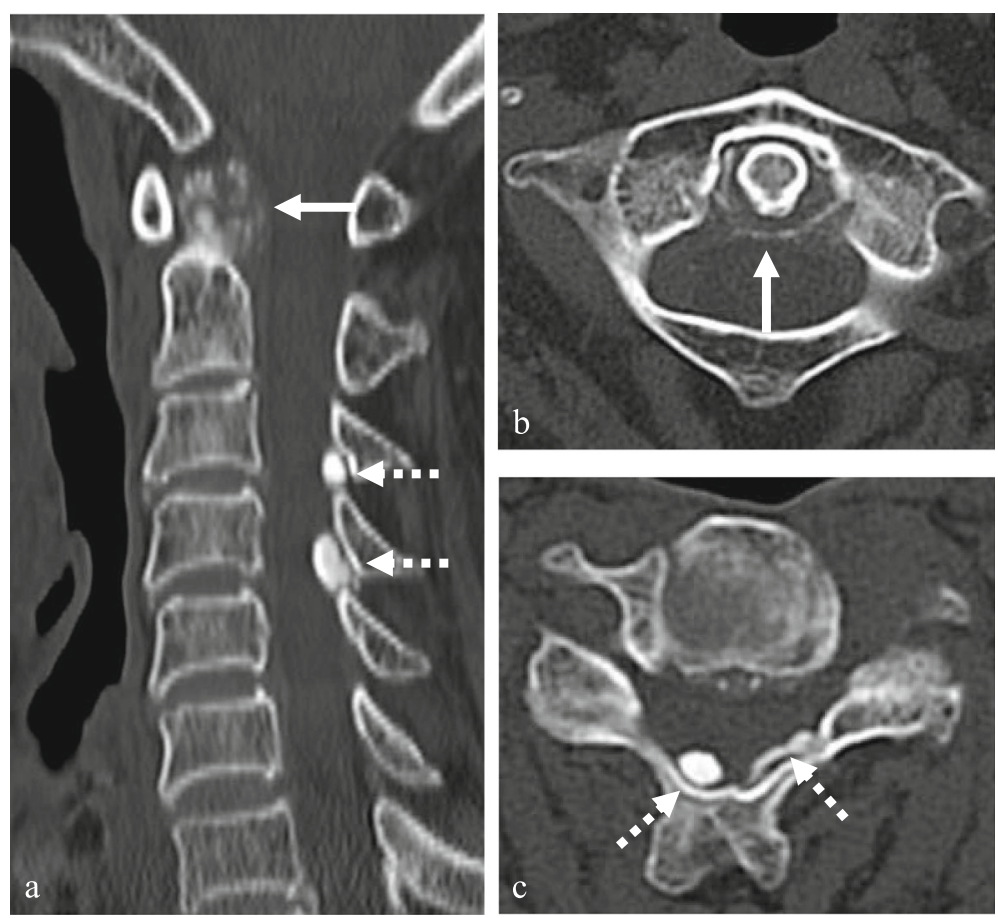

Fig. 6 Sagittal and axial CT scans showed a calcified lesion behind the dens ( $\mathbf{a}$ and $\mathbf{b}$ ) (white arrows) and spinal cord compression by calcified round lesions at C3 and C4 (a and c) (dotted white arrows)

gait disturbance, increased deep tendon reflexes, and pathologic reflexes. Therefore, we believe that CDS was not considered as cause of myelopathy in our two cases. Clinical symptoms are not always correlated with the radiological findings and therefore it is very important to thoroughly evaluate the difference between clinical symptoms and radiologic findings.
CT scans, the most diagnostic examination, demonstrate oval-shaped calcified lesions anterior to the laminae with clear margins [22, 23]. The lesions are observed centrally, not laterally, beneath the laminae. Similarly, in our cases, the lesion appeared to be located in the middle-to-posterior portion of the spinal canal at the $\mathrm{C} 3$ and $\mathrm{C} 4$ level, and it compressed the spinal cord
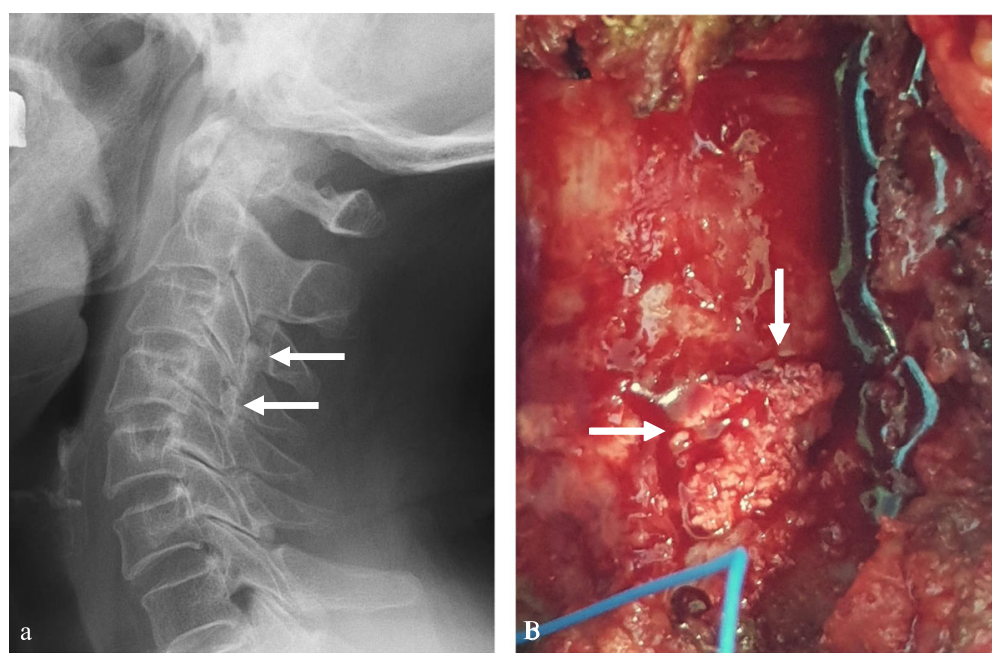

Fig. 7 Lateral radiograph (a) of the cervical spine showed round calcified lesions at the laminae of C3 and C4 (white arrows). Intraoperative clinical photo (b) revealed CPPD deposition after total laminectomy of C3 and C4 (white arrows) 

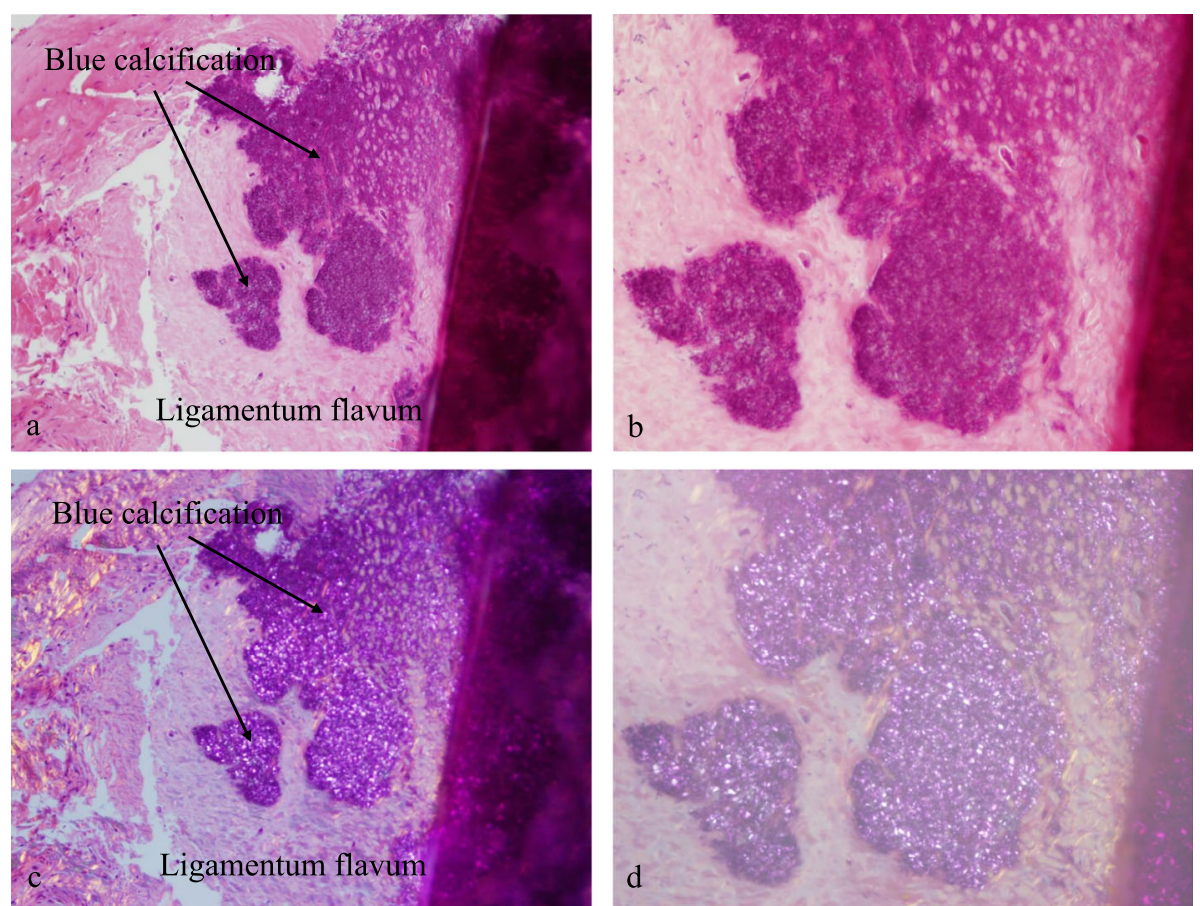

Fig. 8 Microscopic evaluation $(\times 200, \mathbf{a} ; \times 400$, b) of the surgical specimen demonstrated degenerated ligamentum flavum with dark blue calcifications representing chondrocalcinosis. Microscopic evaluation $(\times 200, \mathbf{c} ; \times 400$, $\mathbf{d})$ of the surgical specimen under polarized light showed rhomboid crystals that were positively birefringent in the blue calcification area

posteriorly from the bases of C3 and C4 laminae [1]. On MRI, CPPD deposition manifests as a predominately hypointense area on $\mathrm{T} 1$ and $\mathrm{T} 2$ weighted images, as in the present cases $[3,24,25]$. Moreover, MRI is also useful to assess spinal cord compression or myelopathy [3, 24, 25]. Histology can confirm marked degeneration of elastic fibers about the calcium deposits showing irregular arrangement of the elastic fibers, abnormally small diameter of fragmented elastic fibers, and thick bundles of collagen fibers. Additionally, a number of chondrocytes can be found around the calcium depositioncontaining matrix together with proliferation of small blood vessels and palisading histiocytes and foreign body-type giant cells in the periphery of the calcified lesion [1, 25]. In our study, microscopic evaluation demonstrated degenerative ligamentum flavum with dark blue calcifications, which represented chondrocalcinosis as rhomboid crystals that were positively birefringent in the blue calcification area under polarized light microscope, and these findings were consistent with those of CPPD.

The treatment of CPPD deposition in the cervical spine is based on clinical symptoms [1]. Conservative treatment including medication can be attempted before surgical intervention. However, surgery must be conducted for cervical myelopathy before patients suffer irreversible spinal cord damage $[1,6,8,11,12]$. In each of our cases, we considered conservative treatment as sufficient for the asymptomatic CDS, but surgical treatment was necessary for cervical cord compression due to subaxial CPPD deposition. Consequently, surgical removal of subaxial CPPD deposition achieved a satisfactory surgical outcome and showed a good prognosis without chance of recurrence. In general, the CPPD deposition can be removed by performing decompressive laminectomy for the segments with CPPD, as demonstrated in the second case. However, if there is an associated kyphosis and/or severe spondylosis preoperatively as in the first case, or if there is a need for an excessive decompression including facet joint, it is better to perform a combined fusion procedure for the prevention of the deterioration of symptoms caused by postoperative instability and kyphosis. However, the limitation of this study is case reports and future trials with large sample size are needed to establish our results.

In conclusion, this is the first study to report cervical myelopathy caused by subaxial CPPD deposition with simultaneous asymptomatic CDS. Surgical removal of the subaxial CPPD deposition alone achieved a satisfactory surgical outcome without recurrence.

\section{Abbreviations}

CPPD: Calcium pyrophosphate dehydrate; CDS: Crowned dens syndrome; VAS: Visual analogue scale; mJOA: Modified Japanese Orthopaedic

Association; MRI: Magnetic resonance imaging; CT: Computed tomography 


\section{Acknowledgments}

None.

\section{IRB status}

This retrospective study was approved by the Institutional Review Board of the Uijeongbu St. Mary's Hospital and informed written consent was obtained from the patient for publication of this study and accompanying images.

\section{Authors' contributions}

DGC: Writing-original draft, Writing-review \& editing.: JBP: Conceptualization, Resources, Supervision, Project administration.: HYJ: Validation, Data curation.: KJS: Visualization. All authors have read and approved the final manuscript.

\section{Funding}

The authors indicated that there was no external funding for this study.

\section{Availability of data and materials}

Not applicable as this is a case report.

\section{Ethics approval and consent to participate}

This case report was approved by the Institutional Review Board of the Uijeongbu St. Mary's Hospital.

\section{Consent for publication}

The authors have obtained the patient's written informed consent for print and electronic publication of this case report.

\section{Competing interests}

The authors declare that they have no conflict of interest.

\section{Author details}

'Department of Orthopaedic Surgery, Inje University Sanggye Paik Hospital, College of Medicine, Inje University, Seoul, South Korea. ${ }^{2}$ Department of Orthopaedic Surgery, College of Medicine, The Catholic University of Korea, Seoul, South Korea. ${ }^{3}$ Department of Orthopaedic Surgery, Uijeongbu St. Mary's Hospital, College of Medicine, The Catholic University of Korea, 271 Cheonbo-ro, Uijeongbu-si, Gyeonggi-do 11765, South Korea. ${ }^{4}$ Department of Pathology, College of Medicine, The Catholic University of Korea, Seoul, South Korea.

Received: 2 July 2020 Accepted: 23 October 2020

Published online: 31 October 2020

\section{References}

1. Baba H, Maezawa Y, Kawahara N, et al. Calcium crystal deposition in the ligamentum flavum of the cervical spine. Spine (Phila Pa 1976). 1993;18: 2174-87.

2. Turaga S, Thomas M, Savy L, et al. Pseudogout or pseudolymphoma? Calcium pyrophosphate deposition disease of the cervical spine: a rare presentation and literature review. BMJ Case Rep. 2019;12:e231508.

3. Wada N, Yamashita K, Hiwatashi A, et al. Calcium pyrophosphate dihyrate crystal deposition disease of the spinal dura mater: a: case report. BJR Case Rep. 2017:4:20170049.

4. Bridges $\mathrm{KJ}$, Bullis $\mathrm{CL}$, Wanchu $\mathrm{A}$, et al. Pseudogout of the cervical and thoracic spine mimicking infection after lumbar fusion: case report. J Neurosurg Spine. 2017;27:145-9.

5. Morino T, Ogata T, Horiuchi $H$, et al. Eight years of follow-up after laminectomy of calcium pyrophosphate crystal deposition in the cervical yellow ligament of patient with Coffin-Lowry syndrome: A case report Medicine (Baltimore). 2016;95:e4468.

6. Parker GD, Jones NR, Scott G. Cervical myelopathy in C.P.P.D. deposition disease. Australas Radiol. 1990;34:82-5.

7. $\mathrm{Ng}$ IB, Arkun K, Riesenburger RI. Posterior C1-C2 calcium pyrophosphate dihydrate crystal deposition disease. BMJ Case Rep. 2016;2016: bcr2016214771.

8. Klineberg E, Bui T, Schlenk R, et al. Retro-odontoid calcium pyrophosphate dehydrate deposition: surgical management and review of the literature. Evid Based Spine Care J. 2014;5:63-9.

9. Lee GS, Kim RS, Park HK, et al. Crowned dens syndrome: a case report and review of literature. Korean J Spine. 2014;11:15-7.
10. Uh M, Dewar C, Spouge D, et al. Crowned dens syndrome: a rare cause of acute neck pain. J Clin Rheumatol. 2013;32:711-4.

11. Lin SH, Hsieh ET, Wu TY, et al. Cervical myelopathy induced by pseudogout in ligamentum flavum and retro-odontoid mass: a case report. Spinal Cord. 2005:44:692-4.

12. Srinivasan A, Belanger $\mathrm{E}$, Woulfe J, et al. Calcium pyrophosphate dihydrate deposition disease resulting in cervical myelopathy. Can J Neurol Sci. 2005; 32:109-11.

13. Zünkeler $B$, Schelper $R$, Menezes $A H$. Periodontoid calcium pyrophosphate dihydrate deposition disease. J Neurosurg. 1996;85:803-9.

14. Sato R, Takahashi M, Yamashita Y, et al. Calcium crystal deposition in cervical ligamentum flavum: CT and MR findings. J Comput Assist Tomogr. 1992;16:352-5.

15. Kawano N, Matsuno T, Miyazawa S, et al. New knowledge on the calcium pyrophosphate dihydrate (CPPD) crystal deposition disease in the cervical ligamentum flavum. No Shinkei Geka. 1987;15:181-90.

16. Salaffi F, Carotti M, Guglielmi G, et al. The crowned dens syndrome as a cause of neck pain: clinical and computed tomography study in patients with calcium pyrophosphate dihydrate deposition disease. Clin Exp Rheumatol. 2008:26:1040-6.

17. Sekijima Y, Yoshida T, Ikeda S. CPPD crystal deposition disease of the cervical spine: a common cause of acute neck pain encountered in the neurology department. J Neurol Sci. 2010;296:79-82.

18. Hamilton EB. Disease associated with CPPD deposition disease. Arthritis Rheum. 1976;19:353-7

19. Roet M, Spoor JK de Waal M et al. Extensive calcification of the ligamentum flavum causing cervical myelopathy in a Caucasian woman. Springerplus. 2016;5:1927.

20. Goto S, Umehara J, Aizawa T, et al. Crowned dens syndrome. J Bone Joint Surg Am. 2007;89:2732-6.

21. Matsumura M, Hara S. Images in clinical medicine. Crowned dens syndrome. N Engl J Med. 2012;367:e34.

22. Chang EY, Lim WY, Wolfson T, et al. Frequency of atlantoaxial calcium pyrophosphate dihydrate deposition at CT. Radiology. 2013;269:519-24.

23. Haikal A, Everist BM, Jetanalin P, et al. Cervical CT-dependent diagnosis of crowned dens syndrome in calcium phosphate dihydrate crystal deposition disease. Am J Med. 2020;133:e32-7.

24. Moshrif A, Laredo JD, Bassiouni H, et al. Spinal involvement with calcium pyrophosphate deposition disease in an academic rheumatology center: a series of 37 patients. Semin Arthritis Rheum. 2019;48:1113-26.

25. Finckh A, Van Linthoudt D, Duvoisin B, et al. The cervical spine in calcium pyrophosphate dihydrate deposition disease. A prevalent case-control study. J Rheumatol. 2004;31:545-9.

\section{Publisher's Note}

Springer Nature remains neutral with regard to jurisdictional claims in published maps and institutional affiliations.

Ready to submit your research? Choose BMC and benefit from:

- fast, convenient online submission

- thorough peer review by experienced researchers in your field

- rapid publication on acceptance

- support for research data, including large and complex data types

- gold Open Access which fosters wider collaboration and increased citations

- maximum visibility for your research: over $100 \mathrm{M}$ website views per year

At BMC, research is always in progress.

Learn more biomedcentral.com/submissions 